\title{
Lexical Cohesion in Research Articles ${ }^{i}$
}

\author{
Jiayu Wang*, Yi Zhang \\ School of Foreign Studies, Northwestern Polytechnical University, China
}

Copyright $\subseteq 2019$ by authors, all rights reserved. Authors agree that this article remains permanently open access under the terms of the Creative Commons Attribution License 4.0 International License

\begin{abstract}
This study examines how academic writers use lexical cohesion (LC) in research articles (RAs) and what the features of LC are, since the appropriate use of LC promotes the coherence of academic discourse. Through stratified random sampling, 30 articles were selected from Applied Linguistics. With the adoption of Coh-Metrix and manual coding, the analysis found that repetition was overwhelmingly-used (91\%) in scholarly journal writings, whereas hyponymy was adopted least, only occupying $1 \%$ collectively. Moreover, the use of LC significantly related to the structure of RAs, that is, Introduction, Methodology, Results and Discussion/conclusion (IMRD) $\left(\chi^{2}=29.476, p=.000\right.$ $<.05)$. LC, as a whole, is most frequently-used in Introduction. The adoption of repetition, synonymy, and meronymy significantly related to IMRD structure. Furthermore, it is assumed that synonymy is prone to be context-dependent, in the meanwhile, hyponymy and antonymy are content-oriented. Ultimately, it is hoped that the ways concluded to use LC can help writers build coherent discourse in academic writings.
\end{abstract}

Keywords Lexical Cohesion, Research Articles, IMRD

\section{Introduction}

If the main ideas conveyed by a writer are regarded as the skeleton [1] of a text, an article or a book, lexical cohesion (LC) is its blood; conversely, the grammatical cohesion like substitution, reference, conjunctions and so on [2] are blood vessels. Only playing the role of scaffolds for the text development, they have less semantic implications, compared with LC. LC even often overlaps the keywords or topics in a text. For this reason, following LC chains, readers can uncover its skeleton. According to Systemic Functional Grammar (SFG), unlike grammatical cohesive devices, lexical cohesion (LC) carries no obvious signals of their cohesive functions [3].But they effectively play the main roles of organizing texts. Mostly, the identification of LC is more difficult than that of grammatical cohesion. As for readers, this may be attributed to their unawareness. However, once they realize, LC could be a sharp tool for quick reading, especially when they read research articles (RAs). Since Hyland stated that grammatical cohesive devices like replacement or pronouns were rarely used in scientific texts [3], LC became the major hints for the development of texts. What is more, academic discourse has "high lexical density" [4]. From this perspective, lexical cohesion has more important influences on discourse coherence. Coherence is, in essence, a feeling [5] or a mental model [6] for readers, and measurable regarding readers' assessment [5]. Therefore, it is hard to figure out whether a text is coherent or not. To research on coherence requires the examining of the cohesion used in texts, because cohesion is considered as the "surface-structure" of coherence [6]. What is more, LC, as one of cohesive links, help writers organize the academic text. Therefore, the using of cohesion is vital for constructing a coherent academic discourse.

Writers' adoption of lexical devices is one primary way of "creating continuity in their messages" [3]. Although LC functions as a local device in a text, it is still reasonable to view how LC contributes to the coherence of the whole text, since the forming of the lexical cohesive chain [2] can back this statement. In contrast, most previous research on LC paid attention to its functions exerted in several sentences or paragraphs. The broad picture of LC was underestimated. In the present research, not only LC in each section, Introduction, Methodology, Results and Discussion/conclusion (IMRD) of RAs is elucidated, but how it is used in whole RAs is also explained. A coherent text contributes to the success of information transmission. In this light, the holistic view is also used to combine these two elements. The goal of this study is to probe into how academic writers use LC to create discourse at both the macro and micro level. The research questions are as follows:

(1) What are the features of LC used in the whole RAs?

(2) What are the features of LC used in each section of RAs? 


\section{Lexical Cohesion}

\subsection{Definition of Lexical Cohesion}

The most widely-used instructions of LC are from Halliday \& Hasan. It is "the cohesive effect achieved by the selection of vocabulary". Thompson named LC as "cohesive signal" [7]. He also mentioned that writers felt obliged to help readers achieve coherence-construction through drawing on cohesive signals. It indirectly affirms that cohesive chunks are the signals sent to readers from writers. Overall, though most scholars see eye to eye with each other on the connotation of LC, different classifications are put forward. Hoey mentioned that LC especially repetition formed "matrices"[5]. They can also be called "net" throughout the whole text, which consists of lexical bonds.

Under the framework of SFG, the uniqueness of LC lies in its cross-level feature that is between lexicogrammatical and semantic level. Due to its lexical and semantic features, LC shoulders more responsibilities to assist writers to "manipulate the mind of readers" [7]. Tracing cohesion devices, readers can wrestle with the enigma of the text and "meet writers halfway" [8]. McCarthy defined the LC as "systematic and patterned way for interactive purposes" [8]. From the psychological perspective, LC is proved to have psychological reality. Fitzpatrick, Playfoot, Wray \& Wright designed a cue-and-response research, during which some words were given, and cohorts were required to write down the very lexicon or phrase appearing in their mind immediately [9]. The result showed that synonyms, hyponyms, and collocations are the most frequently-triggered words. They are classified as LC devices by Halliday \& Hasan.

\subsection{Classification of Lexical Cohesion}

Halliday \& Hasan proposed a primary classification of LC including repetition, hyponymy, synonymy, antonymy, meronymy, and collocation. The original interpretation of reiteration only refers to repetition, synonym, superordinate, and general word. It seems that the obstacles in empirical research push Hasan [10] to further illustrate the reiteration. Only repetition and synonymy were retained, and hyponymy, meronymy, and antonymy were added in. Halliday [11] highlighted that the vertical relations in hyponymy like "animal-dog" are one types of LC, meanwhile, the horizontal ones like "dog-horse-goose" should not be neglected either. The situation is much like referring to meronymy. For instance, "finger" is a meronym to "hand", in the meantime, the relations between "forefinger" and "ring finger" are co-meronyms. Consequently, co-hyponymy and co-meronymy become the newcomers in Halliday's classification of LC.

Although Halliday \& Hasan only used limited space to clarify LC, their classification stood out as a landmark, and the later divisions were derived from it [12-14]. Hoey named collocation as "a ragbag" of LC, which implied the difficulties to discern it. Researchers are required to have sufficient background knowledge and also cultural connotations to select collocations from the lexicon pool. Morris \& Hirst's classification [12] is mainly derived from Halliday \& Hasan's [2]. The difference is that meronymy and antonymy are both included in collocation, and considered as systematic semantic collocations. Martin [13] initiated to describe LC by adopting the model. For example, scale and delicacy in each sub-model of LC were depicted. Taxonomy, nuclear and activity are the three major types of LC summarized by Martin [13]. Sinclair [14] stated that semantic reference and semantic prosody both were the sub-sects of LC. The distinct characteristics of colligation and collocation were sorted out. However, there are still gaps to be filled in the LC research. The classification of LC is far from clearcut. Let alone using the computer to discern every type of LC device. For instance, the aforementioned "ragbag", collocation, is hard to define. Barely have studies reported convincing methods to identify collocation. Although this research will not propose a new classification of LC, it attempts to conclude how LC contributes to the coherence of academic discourse.

\section{Academic Discourse}

\subsection{The Features of Academic Discourse}

The first feature of academic discourse is that it shows the characteristics of a "discourse community" and mirrors "disciplinary culture", especially for the articles in the high impact journals. It is why the current research draws on published papers from a top journal in an academic area. To some degree, it is the best way to understand the disciplinary culture and how the writer in the field interacts with their peers.

The investigation of academic discourse inevitably refers to the roles of writers and readers. Due to the writer's intention of persuading the readers, academic discourse shows the highest non-narrative value. The genre of academic discourse determines that it displays more functions of persuading readers, and citations are the most salient evidence [15]. Because of readers' postulated role in written discourse, their spontaneous feedback is invisible, so searching for the first-hand experience is far from easy. An "imaginary conversation" [15] should be speculated by the authors of any RAs. Heller \& Morek [16] also reported that the core feature of it was "knowledge transmission". LC, as a particular writing strategy, could be the most straightforward method.

\subsection{IMRD Structure of Academic Discourse}


Academic discourse, especially scholarly journal articles, usually have comparatively fixed rhetoric structure. In this research, RA, a type of academic discourse, is mainly examined. RAs are named as "lifeblood" [17] in academic colonies, especially articles from the top journal, which usually shed light on the current outcomes and the future orientation of a discipline. As for the rhetoric structure of RAs, Swale's [18] Introduction - Methodology - Results Discussion/conclusion (IMRD) structure is recognized as a "prototypical structure" [19]. It is displayed in figure 1.

The reason why the structure needs to be highlighted is that it implies the coherence of RA in a macro level, just as what Silver [20] stated "categories in transition", whereas the appropriate use of LC supports the development of inner coherence of a text. It stands on its feet on a micro level. For this reason, it is necessary to combine both macro and microstructure, so the coherence of the whole article can be obtained.

\section{Methodology}

The pool of samples consists of 30 RAs from the journal Applied Linguistics, with an average word count of 7110.97 and the total number of 213329. In terms of one characteristic of LC, that is, frequently occurring in the texts, the number of 200 thousand is sufficient to carry on research about $\mathrm{LC}$, as $\mathrm{Xu} \& \mathrm{Xu}$ [21] indicated. The research made use of stratified random sampling and selected three articles per year over the span of 2008 to 2017. In all, the 30 articles cover various topics in the field of applied linguistics, such as discourse analysis, corpus linguistics, second language acquisition, bilingualism, and multilingualism.

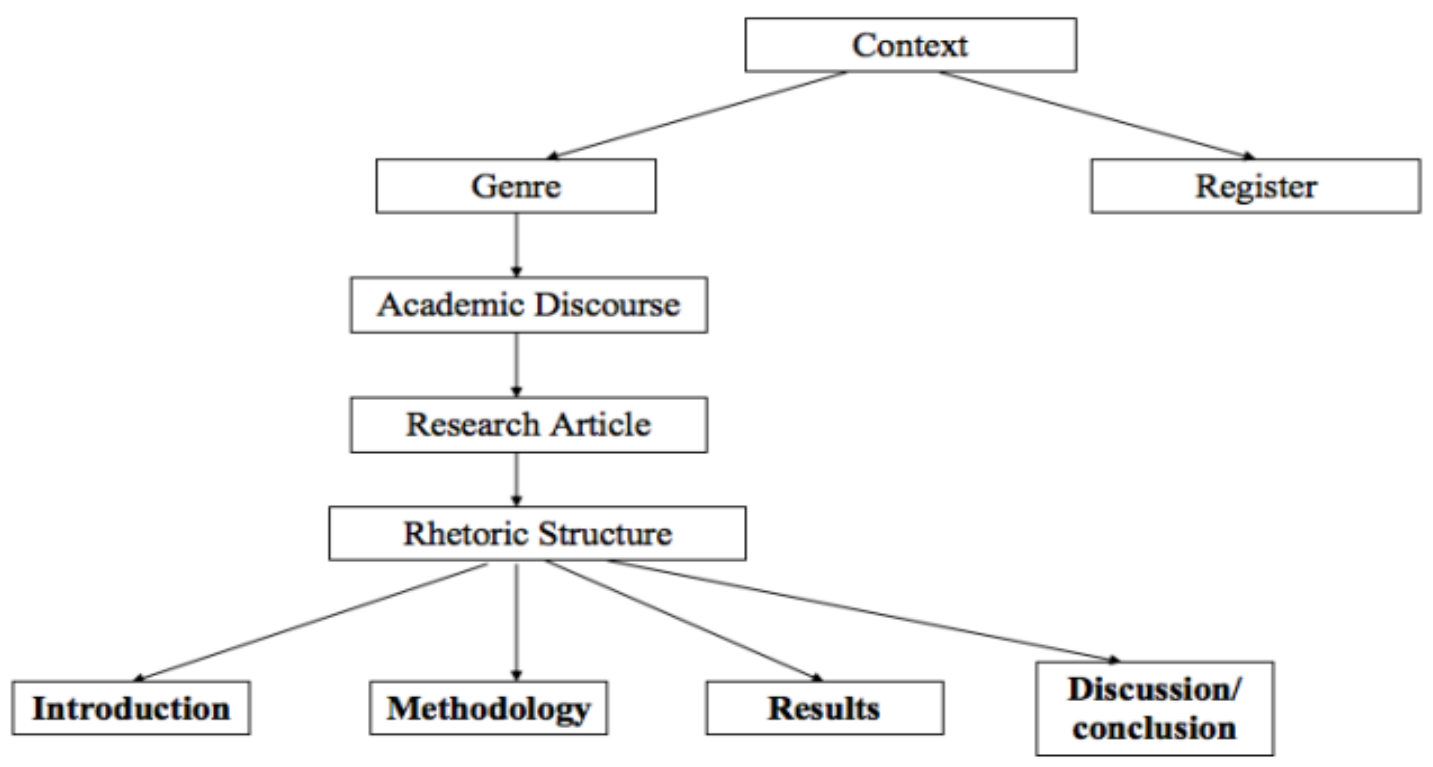

Figure 1. The Genre in this Study 


\subsection{Operational Definitions of Lexical Cohesion}

Repetition helped establish the relationships between sentences [22], and could even organize "book-length" texts. In terms of LC's features, the repetition of functional words was neglected. While repetition does not strictly restrict that only the same words can be counted as repetition, the words sharing the same content morphemes are also repetition devices. With the exception of the open-class words like adjectives, adverbs, verbs, and nouns, repetition also includes acronyms, count nouns \& mass nouns, lexical verbs, lexical bundles, and name. Lexical bundles always appear as keywords bundles in RAs. For example, in RA1, "metalinguistic knowledge" is the research topic, and this phrase occurs as a whole. In this situation, it belongs to lexical bundles.

Synonymy indicates overlapping semantic meanings, but it is not always fully intersubstitutable. Researchers took advantage of questionnaires [23] or corpora [24] for finding a common sense on such a "slippery" concept. Absolute synonymy can be discerned easily, and they are the most frequently-used pairs. Meaning potential synonyms are another type of LC, whose meanings are not determined by the discourse in which they appear. For instance, in RA05, "study" and "research" are meaning potential pairs. On the contrary, communication potential is the opposite of meaning potential. It represents the synonymy pairs that are context-dependent. Take RA15 as an example. In this article, "Participants" is equal to "Chinese students" or "Chinese young adults". They refer to the same group of people in the specific research discourse.

Antonymy was divided into three main types, binary gradable, binary non-gradable, and multiple antonyms [25]. Gradable antonyms contain polar antonyms, committed antonyms, and asymmetrical antonyms. Pairs like "cold" and "hot" are two poles, so they are polar antonyms, while "warm" and "cool" locate in the middle part of two poles, so they belong to committed antonyms. In non-gradable antonymy, three sub-types are also included in. For instance, it is impossible to find a state between "language-related" and "non-language-related". They are thought of as complementaries. Perspectival opposition usually refers to real-world relationships between people. Pairs like "father-mother" and "husband-wife" are the typical examples. Directional opposition includes words in both static and dynamic state. Pairs like "south-north" and "teaching-learning" are all directional oppositions.

Meronymy not only includes the "part-whole" relationship but "part-part" pairs as well. Geeraerts [26] mainly sorted out four types of meronymy, components-entity, material-object, action-activity, and member-collocation. During the tagging procession, it is found that action-activity meronymy pairs frequently occur in Methodology. In the Methods of RA12, the author listed four complex speaking tasks which contained unemployment task, transportation task, hospital task, car park task. In this sentence, the "part-whole" relationship emerges. It could also be found that co-meronymy pairs are also shown in this sentence. However, since the essence of meronyms is about the relationship between "part and whole", co-meronymy is a make-up for the situation when the "whole" is absent. The priority should be given to the "part-whole" relationship, so co-meronymy pairs were not counted in once "part-whole" meronymy pairs appear.

Hyponymy is relatively a less complicated term. It is coined as a sub-property or a super-property. When hyponymy occurs, there is always a signal like "kind of" or "type of". A "pigeon" is a kind of "bird". They are "upper hyponym" with "lower hyponym". As what is analyzed above in meronymy, when upper terms occurred with the lowers, the co-hyponyms were not counted in.

\subsection{Corpus Compilation}

Based on the aim of the research, the very first step of corpus compilation is to divide the RAs into different sections. All 30 RAs are divided following IMRD which is a widely-acknowledged rhetorical organization in this area [27, 28]. Moves and Steps in Introduction [28], Methodology, Results and Discussion/conclusion [28] are the principles followed when dividing the RAs. Ultimately, the 30 samples are turned into four sub-corpus. Introduction corpus includes 30 introductions. Respectively, introduction corpus in total had 62310 words, in the meanwhile, methodology 41312, results 70607 and discussion/conclusion 39100.

\subsection{Research Instruments}

There are in total three instruments are used in this study. The first one is Preview (macOS). It is adapted to tag five different types of LC. The way is to use different colors to highlight each type of LC. Hyland [17] also adopted highlighters to code different moves in academic writings. The Second tool is Coh-Metrix Web Tool which is only used to ensure the reliability of the data coded manually. The "referential cohesion" model includes ten indices that stand for overlapped words. These may support the manually coded "repetition" devices. The index hypernymy was used for testing the reliability of hyponymy-coding. SPSS is another instrument used which is especially for inferential analysis. Both independent Chi-square test and Chi-Square Goodness-of-Fit Test were adopted.

\section{Results and Discussion}

\subsection{Results of Lexical Cohesion Devices' Distribution}


The descriptive statistics for the five lexical cohesive devices used in the whole 30 articles are shown in the pie chart below. In total, 12975 occurrences of lexical cohesive devices were discerned.

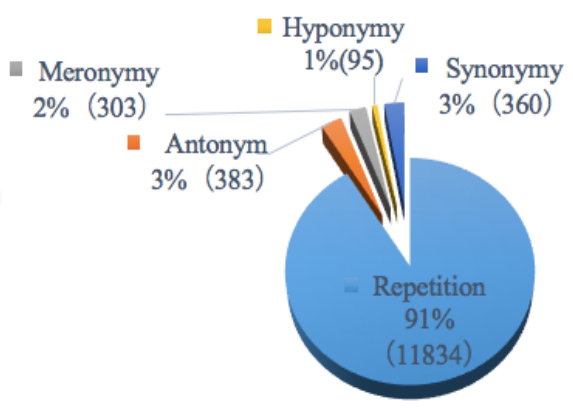

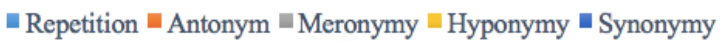

Chart 1. LC Used in RAs
As the chart shows, it was found that the frequency of repetition was used the most (91\%), in marked contrast, hyponymy was used least $(1 \%)$. The proportions of both synonymy and antonymy are 3\% respectively, whereas, meronymy occupies $2 \%$ collectively. Compared with the "huge" number of repetition used, the left four only account for $9 \%$ totally. The descriptive analysis offers an overall picture of the devices' distributions in the RAs. A Chi-Square test was conducted to investigate whether there was a significant relationship between them.

As the table 1 shows, according to Fisher's Exact Test, there is a significant relationship between the using of LC and different sections of RAs $(\chi 2=29.476, p=.000$ $<.05)$. On this ground, the further comparison and contrast of how different LC was used in IMRD will be reasonable.

Table 1. Chi-square Test for LC Used in the Whole RAs

Lexical Cohesive Devices * IMRD Crosstabulation

\begin{tabular}{|c|c|c|c|c|c|c|}
\hline & & \multicolumn{4}{|c|}{ IMRD } & \multirow[b]{2}{*}{ Total } \\
\hline & & Introduction & Methodology & Results & $\begin{array}{l}\text { Discussion/ } \\
\text { conclusion }\end{array}$ & \\
\hline Lexical Cohesive & Repetition & 568 & 448 & 540 & 539 & 2095 \\
\hline Devices & Antonymy & 23 & 14 & 14 & 14 & 65 \\
\hline & Meronymy & 19 & 21 & 9 & 8 & 57 \\
\hline & Hyponymy & 8 & 5 & 3 & 1 & 17 \\
\hline & Synonymy & 22 & 14 & 8 & 26 & 70 \\
\hline Total & & 640 & 502 & 574 & 588 & 2304 \\
\hline
\end{tabular}

\begin{tabular}{|c|c|c|c|c|c|c|c|c|c|}
\hline & \multirow[b]{3}{*}{ Value } & \multirow[b]{3}{*}{ df } & \multirow{3}{*}{$\begin{array}{c}\text { Asymptotic } \\
\text { Significance } \\
\text { (2-sided) }\end{array}$} & \multicolumn{3}{|c|}{ Monte Carlo Sig. (2-sided) } & \multicolumn{3}{|c|}{ Monte Carlo Sig. (1-sided) } \\
\hline & & & & \multirow[b]{2}{*}{ Significance } & \multicolumn{2}{|c|}{ 99\% Confidence Interval } & \multirow[b]{2}{*}{ Significance } & \multicolumn{2}{|c|}{ 99\% Confidence Interval } \\
\hline & & & & & Lower Bound & Upper Bound & & Lower Bound & Upper Bound \\
\hline $\begin{array}{l}\text { Pearson Chi- } \\
\text { Square }\end{array}$ & $29.532^{\mathrm{a}}$ & 12 & .003 & $.000^{\mathrm{b}}$ & .000 & .142 & & & \\
\hline Likelihood Ratio & 30.859 & 12 & .002 & $.000^{\mathrm{b}}$ & .000 & .142 & & & \\
\hline $\begin{array}{l}\text { Fisher's Exact } \\
\text { Test }\end{array}$ & 29.476 & & & $.000^{\mathrm{b}}$ & .000 & .142 & & & \\
\hline $\begin{array}{l}\text { Linear-by-Linear } \\
\text { Association }\end{array}$ & $2.688^{c}$ & 1 & .101 & $.167^{\mathrm{b}}$ & .000 & .342 & $.133^{\mathrm{b}}$ & .000 & .293 \\
\hline $\mathrm{N}$ of Valid Cases & 2304 & & & & & & & & \\
\hline
\end{tabular}

a. 4 cells $(20.0 \%)$ have expected count less than 5 . The minimum expected count is 3.70 .

b. Based on 30 sampled tables with starting seed 2000000 .

c. The standardized statistic is -1.640 . 


\subsubsection{Distribution of Lexical Cohesion Used in RAs}

It is worth noting that since different sections, due to their different functions, their lengths may vary a lot. Consequently, the occurrences of LC per 10000 words were calculated. As table 2 shows,

Table 2. LC Used per 10000 Words in IMRD

\begin{tabular}{cccc}
\hline $\begin{array}{c}\text { Different } \\
\text { Sections }\end{array}$ & $\begin{array}{c}\text { Word Counts } \\
\text { of Different } \\
\text { Sections }\end{array}$ & $\begin{array}{c}\text { Occurrences } \\
\text { of LC }\end{array}$ & $\begin{array}{c}\text { per 10000 } \\
\text { Words }\end{array}$ \\
\hline Introduction & 62310 & 3983 & 639.2 \\
\hline Methodology & 41312 & 2073 & 501.8 \\
\hline Results & 70607 & 4049 & 573.5 \\
\hline $\begin{array}{c}\text { Discussion/ } \\
\text { conclusion }\end{array}$ & 39100 & 2299 & 588.0 \\
\hline
\end{tabular}

Occurrences per 10000 words were the raw data input in SPSS for Chi-Square Goodness-of-Fit Test. The result was shown as follows,

The result reveals that there exists significant difference between the expected and the observed data $\left(\chi^{2}=16.661\right.$, $\mathrm{p}=.001<.05)$. Table 3 also exposes that the difference lies in the uses of both Introduction and Discussion/conclusion. LC is usually adopted most frequently in the Introduction part. To sum up, the Chi-Square test elucidates that writers are prone to make heavy use of lexical cohesive devices in both the Introduction and Discussion/conclusion part. Usually, the number of LC used in the Introduction is larger than its counterpart in Discussion/conclusion.

Since the distribution of LC as a whole is in relation to the rhetoric structure of RAs. It provides a premise for the further examination of how LC as a group used in each section and whether there is a significant difference in the uses of it among IMRD. The following Chi-Square test backs up the prediction that a significant relationship does exist. LC is frequently-adopted in both Introduction and conclusion, yet it occurs more in Introduction. In order to investigate how each LC was used in different sections, the analysis moved forward to the micro level.

Table 3. Chi-Square Test for LC Used in IMRD

\begin{tabular}{|l|r|r|r|}
\hline & Observed $\mathrm{N}$ & Expected $\mathrm{N}$ & Residual \\
\hline Introduction & 639 & 575.8 & 63.3 \\
Methodology & 502 & 575.8 & -73.8 \\
Results & 574 & 575.8 & -1.8 \\
Discussion/ & 588 & 575.8 & 12.3 \\
conclusion & 2303 & & \\
Total & & \\
\hline
\end{tabular}

\begin{tabular}{|l|r|}
\hline & \multicolumn{1}{|c|}{$\begin{array}{c}\text { Different } \\
\text { Sections }\end{array}$} \\
\hline Chi-Square & $16.661^{\mathrm{a}}$ \\
df & 3 \\
Asymp. Sig. & .001 \\
\hline
\end{tabular}

a. 0 cells $(0.0 \%)$ have

expected frequencies

less than 5 . The

minimum expected cell

frequency is 575.8 .

\subsubsection{Distribution of Each Lexical Cohesive Devices Used in IMRD}

\section{(1) Distribution of Repetition Used in IMRD}

Repetition, as the most frequently-adopted lexical cohesive device, basically occurs more than $90 \%$ in each section of RAs. The chart below shows the occurrences of repetition per 10000 words used in each section. The numbers shown in the radar chart are the frequencies of repetition per 10000 words used in IMRD. It is plausible to say that there is no big difference between the uses of the devices. Repetition devices were used respectively 568.2, 538.9 and 539.5 per 10000 words in Introduction, Discussion/conclusion and Results respectively, whereas, they were used much less in Methodology part, by 448.3. Besides, in order to test the reliability of manual coding, the data also inputted in Coh-Metrix. The ten indices of referential cohesion showed that the proportions of nouns, stems and content words overlapped in the introduction were the highest, while these in methodology were the lowest. Basically, the tendency was the same as the results of manual sorting. From this perspective, manual sorting was relatively reliable.

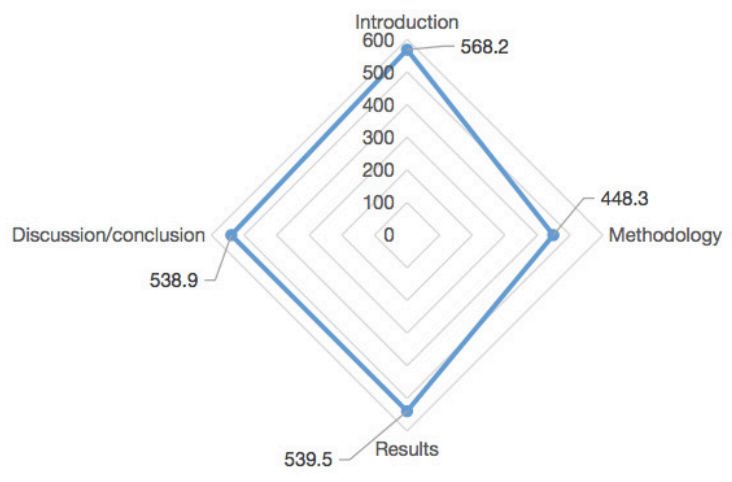

Chart 2. Repetition Used in IMRD (per 10000 words)

The Chi-Square Goodness-of-Fit Test was adopted to verify whether the structure of RAs may influence the using of repetition.

Table 4. Chi-Square Test for Repetition Used in IMRD

\begin{tabular}{|l|r|r|r|}
\hline & Observed $N$ & Expected $N$ & Residual \\
\hline Introduction & 568 & 523.8 & 44.3 \\
Methodology & 448 & 523.8 & -75.8 \\
Results & 540 & 523.8 & 16.3 \\
Discussion/ & 539 & 523.8 & 15.3 \\
conclusion & 2095 & & \\
Total & & \\
\hline
\end{tabular}

Test Statistics

\begin{tabular}{|l|r|}
\hline & \multicolumn{1}{|c|}{$\begin{array}{c}\text { Different } \\
\text { Sections }\end{array}$} \\
\hline $\begin{array}{l}\text { Chi-Square } \\
\text { df }\end{array}$ & $15.642^{\mathrm{a}}$ \\
Asymp. Sig. & 3 \\
a. 0 cells (0.0\%) have \\
expected frequencies \\
less than 5. The \\
minimum expected cell \\
frequency is 523.8.
\end{tabular}


The results displayed above is out of expectation. There is a significant difference between the uses of repetition with the structure of RAs $\left(\chi^{2}=15.642, p=.001<.05\right)$. The differences are shown by the using of LC in the sections of Introduction, Methodology and Discussion/conclusion.

\section{(2) Distribution of Antonymy Used in Four Parts of RAs}

The second lexical cohesive device to-be-tested is antonymy. The descriptive data of antonymy used in different sections are displayed in the chart below.

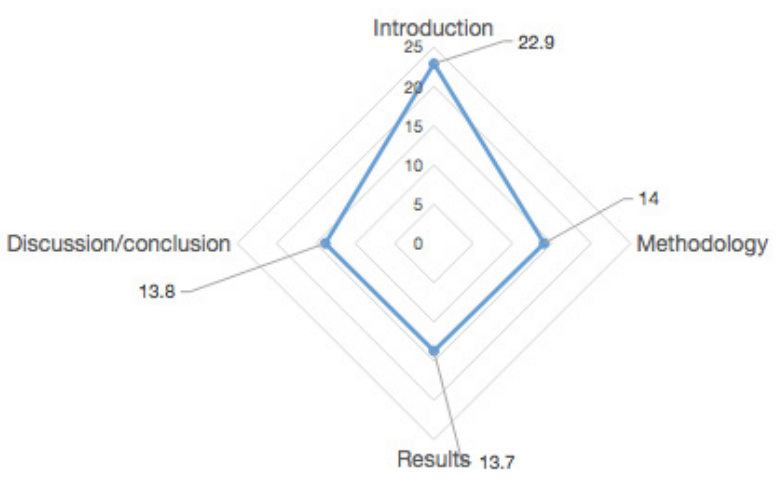

Chart 3. Antonymy Used in IMRD (per 10000 words)

The radar chart illustrates that Antonymy was used much more in Introduction than in the left three parts (I: 22.9; M:14; R:13.7; D:13.8).

Table 5. Chi-Square Test for Antonymy Used in IMRD

\begin{tabular}{|l|r|r|r|}
\hline & Observed N & Expected N & Residual \\
\hline Introduction & 23 & 16.3 & 6.8 \\
Methodology & 14 & 16.3 & -2.3 \\
Results & 14 & 16.3 & -2.3 \\
Discussion/concl & 14 & 16.3 & -2.3 \\
usion & 65 & & \\
Total & & & \\
\hline
\end{tabular}

Test Statistics

\begin{tabular}{|l|r|}
\hline & \multicolumn{1}{|c|}{$\begin{array}{c}\text { Chi-square } \\
\text { Test on } \\
\text { Antonymy } \\
\text { Used in IMRD }\end{array}$} \\
\hline Chi-Square & $3.738^{\mathrm{a}}$ \\
df & 3 \\
Asymp. Sig. & .291 \\
\hline
\end{tabular}

a. 0 cells $(.0 \%)$ have expected frequencies less than 5 . The minimum expected cel frequency is 16.3 .

The Chi-Square test shed lights on that there was no significant difference between the using of antonymy and the organization of RAs $\left(\chi^{2}=3.738, \mathrm{p}=.291>.05\right)$. Thus, the further discussion will not be about the relationship between the using of antonymy and the structure of RAs. It seems that no valuable instructions about the features of antonymy used in journal articles could be given to for either academic writers or readers.

\section{(3) Distribution of Meronymy in IMRD}

The distribution of meronymy is manifested through a radar chart as is adopted above. The data input was also turned into the numbers of meronymy used per 10000 words.

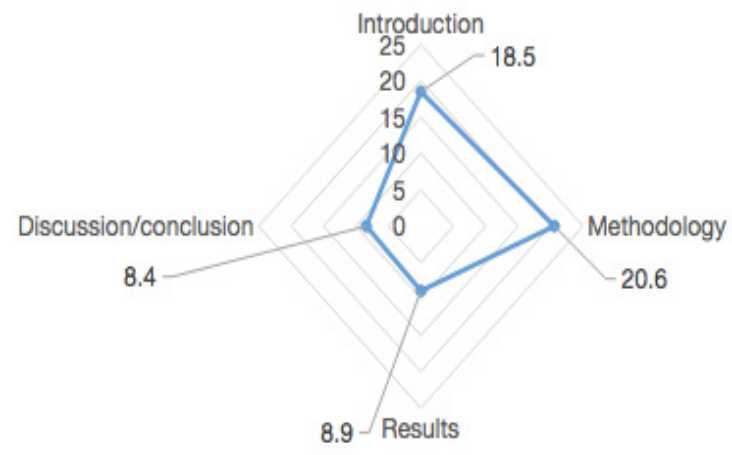

Chart 4. Meronymy Used in IMRD (per 10000 words)

As is expressed by the chart above, the numbers of meronymy used by writers are similar in both Discussion/conclusion and Results, in the meanwhile, the frequencies per 10000 words of it used in Introduction and Methodology are also close to each other. It is why the radar chart displayed as a form of a parallelogram. The Chi-Square test will help examine the relationship between the using of meronymy and IMRD structure.

The test indicates that there is a significant difference between the expected count and observed count of the meronymy used in different sections $\left(\chi^{2}=9.456, \mathrm{p}=.024\right.$ $<.05$ ). The difference is caused by its use in both Introduction and Methodology. In addition, table 6 also elucidates that the use of meronymy in Methodology is more than that in the introduction.

Table 6. Chi-Square Test for Meronymy Used in IMRD

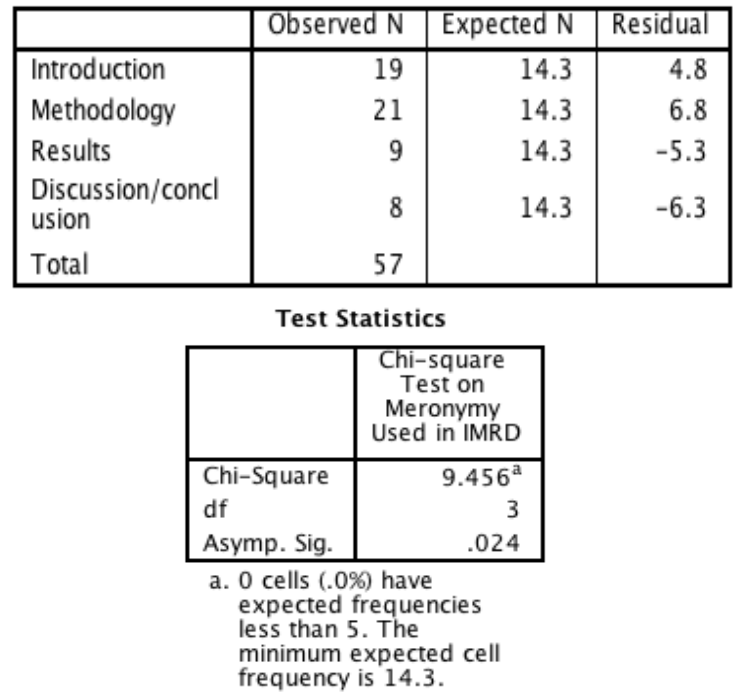




\section{(4) Distribution of Hyponymy in IMRD}

Hyponymy, as the least-used lexical cohesive device in RAs, was found quite different on its using in IMRD. To test the reliability of data, one index WRDHYPn in Coh-Metrix showed that hyponymy was used least in the discussion. It corroborated with the result of manual coding.

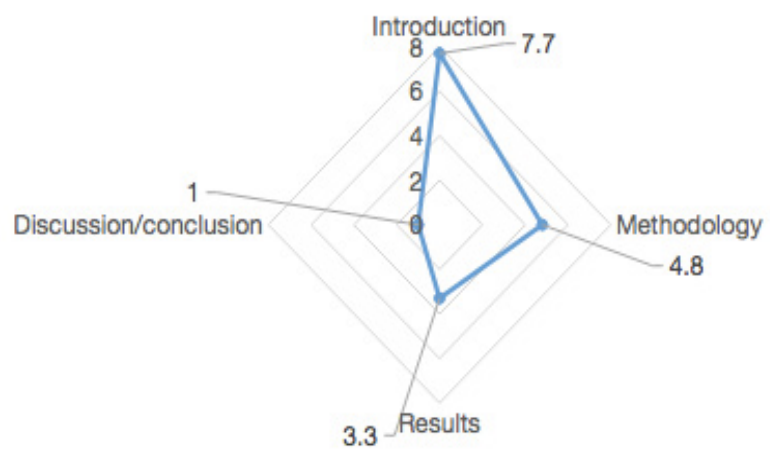

Chart 5. Hyponymy Used in IMRD (per 10000 words)

Hyponymy was barely used in Discussion/conclusion, whereas it was relatively used more in Introduction (7.7). It seems that the occurrence of hyponymy is extremely low, which may be relevant to manual sorting. However, the previous research mirrors the result. Tanskanen [3] selected out four academic articles and coded the LC manually. The average number of reiteration used was about 90 per 1000 words, thus, in total, reiteration used per 10000 words would be around 9. As illustrated in Section 2.1.2.1, reiteration includes all the five lexical cohesive devices. From this perspective, it is possible that hyponymy only occurred once per 10000 words. Besides, whether there is a significant difference between the observed and expected count still needs to be tested.

Table 7. Chi-Square Test for Hyponymy Used in IMRD

\begin{tabular}{|l|r|r|r|}
\hline & Observed N & Expected N & Residual \\
\hline Introduction & 8 & 4.3 & 3.8 \\
Methodology & 5 & 4.3 & .8 \\
Results & 3 & 4.3 & -1.3 \\
Discussion/concl & 1 & 4.3 & -3.3 \\
usion & 17 & & \\
Total & & \\
\hline
\end{tabular}

Test Statistics

\begin{tabular}{|l|r|}
\hline & \multicolumn{1}{|c|}{$\begin{array}{l}\text { Chi-square } \\
\text { Test on } \\
\text { Hyponymy } \\
\text { Used in IMRD }\end{array}$} \\
\hline Chi-Square & $6.294^{\mathrm{a}}$ \\
df & 3 \\
Asymp. Sig. & .098 \\
\hline
\end{tabular}

a. 4 cells $(100.0 \%)$ have expected frequencies less than 5 . The minimum expected cell frequency is 4.3 .
Obviously, there is no significant difference between the two counts $\left(\chi^{2}=6.294, p=.098>.05\right)$. It implies that, in terms of its frequencies, the general user of hyponymy may not vary saliently from one section to another.

\section{(5) Distribution of Synonymy Used in IMRD}

Synonymy accounted for 3\% collectively in the whole RAs. It was also counted in different sections. The chart below shows the detailed information.

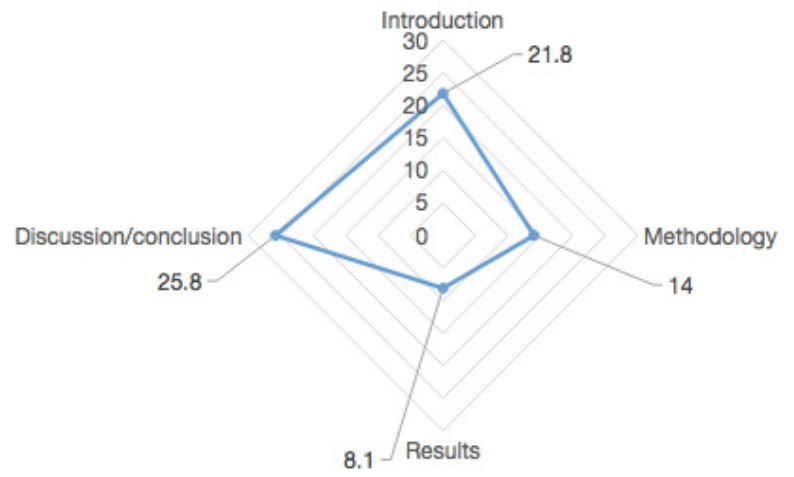

Chart 6. Synonymy Used in IMRD (per 10000 words)

It is disclosed that synonymy is descriptively used least in

Results (8.1). In contrast, the using of synonymy in

Discussion/conclusion is three more times than that in Results, about 25.8 per 10000 words.

Table 8. Chi-Square Test for Synonymy Used in IMRD

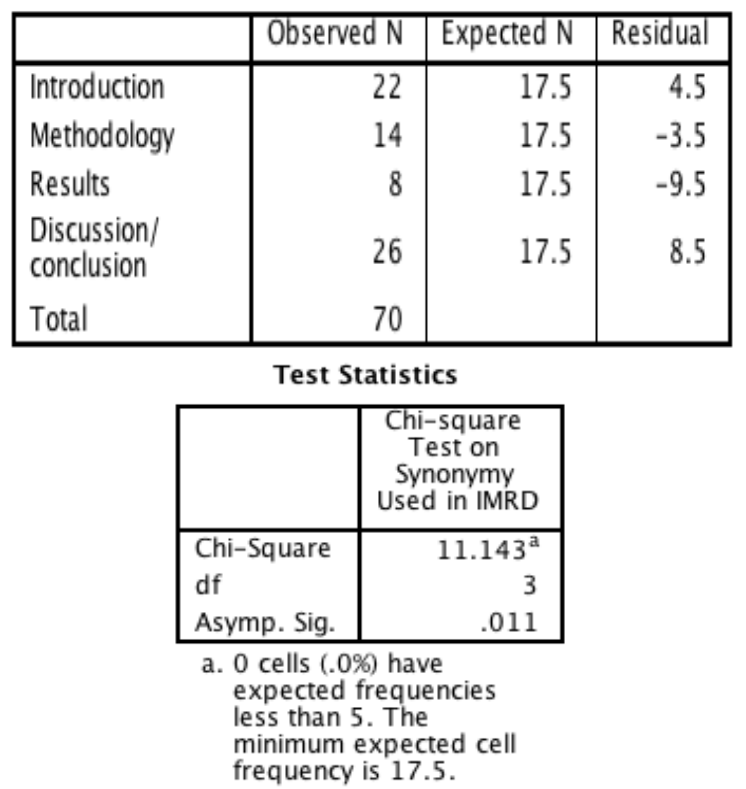

The results of Chi-square test indicates that there is a significant difference between both expected and observed count when it comes to the using of synonymy in $\operatorname{IMRD}\left(\chi^{2}=11.143, \mathrm{p}=.011<.05\right)$. The difference was brought about by the uses of Synonymy in both introduction and discussion/conclusion. 


\subsection{Discussion of Lexical Cohesion in Sub-sections}

Based on the descriptive and inferential statistics, the features of LC will be examined. It is worthwhile noting that the characteristics will be analyzed around two main perspectives, the frequencies and the positions of each LC device.

\subsubsection{The Use of Repetition}

The form of the radar shown in chart 2 is nearly a square which, in a broad view, elucidates that the distributions of repetition in different sections are almost on average. Yet the inferential analysis afterward shows that the significant differences between the expected values with the observed values are found in the use of repetition in the introduction, results, and discussion/conclusion parts.

Repeated words occur most-frequently in the introduction part. Two reasons may reveal why repetition is particularly used in the section of introduction. It is determined by the functions of introduction. Firstly, an essential role that introduction plays is to introduce the key terms of the article and explain what is mainly illustrated in the whole text. In order to help readers understand the core notions, writers usually adopt repetition which may deepen the author's memorization of them rather than increasing disconnected information pieces to confuse readers. The introduction is "high-visibility" [29], and clear interpretation is the overarching goal. Secondly, as what is observed, the highly repeated content words in the Introduction is the topic of the article. For example, in RA30, "language ideology" (including language ideologies) reoccurs 29 times in the introduction part. The title of this article "Corpus Approaches to Language Ideology" contains the term as well. In RA09, "English" appears mostly, accounting for 14 times, although it doesn't occur in the title of RA09. In this light, they back up the opinion that usually repetition is used in the introduction to highlighting the key points and arousing readers' attention.

In the results part, the repeated contents are proved to be distinguished from the ones in the introduction part. When the information goes along the conveyor belt into the section of methodology and results, it will be reprocessed, namely, operationalized. Just as what we exemplify above, "language ideology" and "English", in a sense, are general and vague, the detailed analysis of these notions usually appear in the sections of M and R. Take RA06 as an example.

Table 9 reveals the situation in which four different content words occur. Saliently, the similarity of these four is that they only emerge in the results parts. Through reading the article, it is found that the topic of RA06 is "topic negotiation", the author did not mention the exact topics that participants talked about until it came to the results part. In that part, the author used the discourse to examine on how interlocutors communicate with each other around the topics like "character" and "feather" with their sub-topics "chocolate" and "bird". It does not mean that there are cracks in the information flow In effect, the writers had narrowed down the topics. In addition, the high ratio of repetition in results is also in relation to the results' own feature namely, "cyclicity" [28]. The using of repetition in this section is to emphasize the outcome gained.

The discussion/conclusion part witnesses the relatively frequent using of repetition. Comparatively, Introduction is for bringing new knowledge in while discussion/conclusion section usually mulls over the key information. Through observing what is repeated in the introduction, it is found that most contents recurred are similar to the ones in the last section. Taking RA06 as an instance, the gathering places for the keyword "topic" in that text are the introduction and discussion/conclusion parts. Information becomes more complicated in Methodology and Results, whereas it is expressed in relatively graspable and superficial ways in Introduction and Discussion. Bitchener [30] pointed out that as the RAs in other areas, these in applied linguistics also contain the information in the discussion part like comparing the results with others', or how they contribute to theories in this field. If the writer still tangles with the details rather than going back to the general terms introduced in the first section of RA, the articles may fail in distilling new knowledge.

Table 9. Frequency of Four Repeated Content Words in RA06

\begin{tabular}{ccccc}
\hline Repeated Lexis & $\begin{array}{c}\text { Its Frequency in } \\
\text { Introduction }\end{array}$ & $\begin{array}{c}\text { Its Frequency in } \\
\text { Methodology }\end{array}$ & $\begin{array}{c}\text { Its Frequency in } \\
\text { Results }\end{array}$ & $\begin{array}{c}\text { Its Frequency in } \\
\text { Discussion/ conclusion }\end{array}$ \\
\hline character & 0 & 0 & 5 & 0 \\
\hline chocolate & 0 & 0 & 12 & 0 \\
\hline feather & 0 & 0 & 6 & 0 \\
\hline bird & 0 & 0 & 5 & 0 \\
\hline
\end{tabular}




\subsubsection{The Use of Meronymy}

The form of meronymy radar chart is similar to a trapezium. Meronymy is saliently used more in both parts, Introduction and Methodology, while it occurs much less in both Results and Discussion/conclusion. The outcome of the inferential analysis also indicates that there are significant differences between the expected and observed data about the using of meronymy in both Introduction and Methodology.

Loi [31] put forward two main functions of introduction. One is to define the essential terms used in an article, and the other is to specify what the focus of the current research is. In order to give the detailed definitions, one way of defining things is to classify them into a broad concept. Meronymy is usually used as a tool to coin new terms. The following example is extracted from one of the samples in the methods section.

\section{(1) His model of motivation contains two self-related components: Ideal L2 self and Ought-to L2 Self. (RA11)}

The main topic of this article is around learners' motivation. During the introduction part, the author reviews the previous models proposed by other scholars. In the following methods section, based on the antecedents' contributions towards motivation models, the authors put forward theirs.

(2) Three antecedent variables were linked to the criterion measure: the ideal L2 self, the ought-to L2 self, and language learning attitudes. (RA11).

The three variables belong to the model of motivation which is the key point of the article. From this point of view, sometimes, the structure of introduction and that of methodology may overlap. It is, however, still understandable, since any research design should be constructed on the existing theoretical foundations. This writing strategy also prompts the progress of textual coherence. It also reveals that every section though seems separated but they are inner-connected and inconsistency. Cotos, et al. [32] stated that methodology was like an "explicit bridge" between the previous research and the upcoming results section. Analyzing the using of meronymy mirrors the relations between different sections in the articles. LC is partly responsible for tying information in the article, in the meantime, rhetorical structures are for connecting information at a macro level. Both of them commit to the coherence of texts.

\subsubsection{The Use of Synonymy}

The inferential data imply that there are significant differences in the uses of synonymy in both introduction and discussion/conclusion part. The frequency of synonymy is higher in the discussion/conclusion part than that of it in the introduction. Cruse [33] elaborated various types of synonymy. Absolute synonyms are extremely rare, which means that synonymy pairs do not always bear the same meaning in many contexts. Most of the synonyms usually rely on the specific contexts in which they appear and may not have the same lexemes. During the coding session of this research, it is also found that synonymy is context-sensitive. If the context in which the pairs appear changes, most of the words may not be synonyms.

One of the specialties discovered, on the basis of observation, is that the synonyms in introduction usually are not complicated terms. The understandings of the lexis require less background knowledge for readers. For instance, in RA27, the most frequently-used synonyms are "vocabulary", "lexical items", and "words". In RA22, the writers substitute "respondents" with "informants". Readers may not be perplexed by the word transformations since they are familiar with these terms. However, if the writer tries to replace the keywords in the article, they will usually remind readers of the substitution. A counterexample is picked out as follows.

\section{(3) The unintentional retention of information must not, however, be equated with implicit learning. (RA27)}

The "unintentional" seems to have similar entailment with "implicit", so the writer needs to distinguish the two so that they will not confuse the readers. Although it may increase the information load to the sentences, for the readers' convenience, the skillful writers usually will explain clearly [33].

In the conclusion part, writers also possibly interchange the high-frequency words. The difference between it with the introduction is that some new synonymy pairs introduced in the methodology part occur in the conclusion. For example, in RA18, the writer illuminates the basic information about the participants who are Chinese students. This piece of information connects the conclusion with the methodology. Since only if they carefully read the section of methodology, they may immediately understand why the author substitutes "occupants", "participants" with "Chinese students". Another noteworthy point needs to take notice of is that in a context-free situation, "Chinese students" will never be the synonym of the aforementioned two words. Consequently, it proves that practically, the judgment to synonyms highly depends on context. Similar examples can also find in other articles. For example, in the conclusion part of RA05, "school-aged children" is replaced by "students" while "foreigners" by "target language speakers".

This opinion is supported by Cruse [33] and Lyons [25], who consider synonymy containing two meanings presupposed meaning (propositional) and evoked meaning. The former emphasizes the collocation restriction of synonyms, while the latter concerns the register where synonyms used. From this perspective, in conclusion, part, the using of synonymy is more flexible than that of it in 
the introduction section, since, with the overall understanding of the previous parts, readers are projected to have sufficient knowledge to understand synonyms. In addition, this reason can also explain why the writer uses a bit more synonyms in Conclusion, compared with the uses of synonyms in Introduction.

\subsubsection{The Use of Antonymy and Hyponymy}

The uses of antonymy and hyponymy in each section witness no significant differences between their expected and observed values. Compared with the other three lexical cohesive devices, through observation, these two lexical cohesive devices are believed more "content-oriented". Words relations like synonymy, repetition, and meronymy, to some degree, are more applicable in any context, and let alone its contents.

Usually, the occurrences of antonyms are directly determined by the contents of the articles. For example, in RA27, the article is about "implicit and explicit cognitive processes", therefore, as keywords, the antonymy pair "implicit" and "explicit", contributes to the total number of antonymy in the sample. Another example is about a pair of "gradable antonymy". Gradable antonymy is one type of antonymy which does not necessarily occupy two poles but two counter pairs between them. In RA19, the writer compares "content-driven" with "language-driven" two teaching methods. These two may not stand at the opposite sites, but they are gradable antonymy in this occasion. With the exception of the articles containing special contents, in other articles, antonymy belongs to less-frequent devices. In this article, the author distinguishes between "interviewee" and "interviewer".

As for hyponymy, one explanation for why this type of LC occurs the least in almost every section of RA is that hyponymy commonly appears in a sentence pattern "kind of" or "type of" [33]. It is an interpretation from the semantic perspective. Practically, in RAs, in order to ensure the relative preciseness of the academic language and the reliability of their research design, academic writers may use less vague languages. The other reason is that the user of it is similar to that of antonymy analyzed above. They are prone to be content-based. For example,

\section{(4) It has been argued in the literature that peer student interactions are quantitatively and qualitatively different from both the assessor-candidate and teacher-student interactions discussed above. (RA06)}

RA06 examines the "second language learners' peer interactions". In the text, "assessor-candidate interactions" and "teacher-student interactions" are both listed. Obviously, these three different relationships are all "kinds of" interaction. They belong to co-hyponymy. Another instance is that in RA03, three conditions of the formulaic sequence are listed "idiomatic interpretation", "control phrases" and "literal interpretation", which are all "types of" phrases. They are co-hyponymy. To sum up, the using of hyponymy basically refers to the specific content of RAs.

\section{Conclusions}

The quantitative analysis shows that the using of LC significantly relates to the IMRD structure of RA. Repetition is proved to be the most frequently-adopted LC device, whereas hyponymy is the least. To be more specific, repetition is used more in Introduction, Results and Discussion/conclusion. With the aid of repetition, writers attempt to deepen readers' memory of keywords in Introduction, to reinforce the outcomes gained in Results and to imply readers to go back to the general topics in Discussion/conclusion. As for meronymy, it is most frequently used in Introduction and Methodology. It is shown that in both sections, meronymy is used to define key terms and help operationalize the general terms. When it comes to synonymy, it is usually used more in Introduction and Discussion/conclusion. The different feature of synonymy pairs used in these two sections is that the understanding of the pairs used in Introduction requires less background knowledge for readers, whereas in conclusion, these pairs are more discourse-based. The remaining two devices antonymy and hyponymy are thought of as content-oriented words. Their occurrences are mainly determined by the contents of RAs.

In addition, it is found that synonymy is discourse-dependent in most cases, by contrast, antonymy and hyponymy are content-based. These three types of LC have obvious features. When it comes to synonymy, users should bear in mind that absolute synonymy is only a few. The semantic meanings of most synonymy pairs are affected by the discourse of RA where they appear. Besides, the occurrence of antonymy and hyponymy are related to the content of RAs. Their flexibility is much lower than that of the LC like repetition or synonymy. To sum up, the use of LC in RAs are easily-ignored but essential to the discourse coherence. It is expected that this research on the use of LC in both the whole and the sub-sections of RAs may give a clue for academic writers to achieve coherent writing.

\section{REFERENCES}

[1] Adler, M.J. \& Doren, C.V. (1972). How to read a book. 3rd edition. New York: Simon and Schuster.

[2] Halliday, M. A. K. \& Hasan, R. (1976). Cohesion in English. London: Longman.

[3] Tanskanen, S.-K. (2006). Collaborating towards coherence: lexical cohesion in English discourse. Amsterdam, Philadelphia: John Benjamins Publishing. 
[4] Hyland, K. (2006). English for academic purposes. New York: Routledge.

[5] Hoey, M. (1991). Patterns of lexis in text. Oxford: Oxford University Press.

[6] van Dijk, T. (2008). Discourse and context: A sociocognitive approach. New York, Cambridge: Cambridge University Press.

[7] Thompson, G. (2008). Introducing functional grammar. Beijing: Foreign Language Teaching and Research Press.

[8] McCarthy, M. (1992). "Interactive lexis: prominence and paradigms." In M. Coulthard (Ed.), Advances in Spoken Discourse Analysis (pp. 197-208). London \& New York: Routledge.

[9] Fitzpatrick, T., Playfoot, D., Wray, A., \& Wright, M. J. (2015). Establishing the reliability of word association data for investigating individual and group differences. Applied Linguistics, 36(1), 23-50.

[10] Hasan, R. (1984). “Coherence and cohesive harmony. ” In J. Flood (Ed.), Understanding Reading Comprehension: Cognition, Language, and the Structure of Prose. pp. 181219.

[11] Halliday, M. A. K. (1985). An Introduction to Functional Grammar. London: Edward Arnold.

[12] Morris, J., \& Hirst, G. (2006). The Subjectivity of Lexical Cohesion in Text. Computing Attitude and Affect in Text: Theory and Applications. Netherlands: Springer. 20, 41-47.

[13] Martin, J. R. (1992). English text: system and structure. Loan/open Shelves.

[14] Sinclair, J. (2004). Corpus, Concordance, Collocation. Oxford: Oxford University Press.

[15] Hyland, K. (2013). Disciplinary Discourses: Social Interactions in Academic Writing. Ann Arbor: University of Michigan Press.

[16] Heller, V., \& Morek, M. (2015). Academic discourse as situated practice: an introduction. Linguistics \& Education, 31, 174-186.

[17] Hyland, K. (2006). English for academic purposes. New York: Routledge.

[18] Swales, J. (1990). Genre analysis: English in academic and research settings. Cambridge: Cambridge University Press.

[19] Guinda, C. S. (2015). Genres on the move: currency and erosion of the genre move to construct. Journal of English for Academic Purposes, 19, 73-87.

[20] Silver, M. S. (2006). Language across disciplines. Towards a critical reading of contemporary academic discourse. Boca Raton: Brown Walker Press.

[21] Xu, J.J \& Xu, X.L (2016). A comparable corpus based investigation into the cohesive explicitation of translational English, Foreign Languages and Their Teaching, (6), 94-102.

[22] Winter, E. (1979). "Replacement as a fundamental function of the sentence in context." Forum Linguisticum, 4, 95-133.

[23] Liu, D., \& Zhong, S. (2016). L2 vs. 11 use of synonymy: an empirical study of synonym use/acquisition. Applied Linguistics, 37(2), 239-261.

[24] Divjak, Dagmar and Stefan Th. Gries (2006) Ways of trying in Russian: clustering behavioural profiles. Corpus Linguistics and Linguistic Theory 2: 23-60.

[25] Lyons, J. (1996) Linguistic semantics: an introduction. Cambridge: Cambridge University Press.

[26] Geeraerts, D. (2010). Theories of lexical semantics. Oxford: Oxford University Press.

[27] Lin, L., \& Evans, S. (2012). Structural patterns in empirical research articles: a cross-disciplinary study. English for Specific Purposes, 31(3), 150-160.

[28] Yang, R.Y. (2006). Application of genre analysis: Analyzing the structure of applied linguistics research articles. Foreign Languages and Their Teaching, (10), 29-34.

[29] Canagarajah, A. S. (2002). Critical academic writing and multilingual students. Ann Arbour, MI: University of Michigan Press.

[30] Bitchener, J. (2010). Writing an Applied Linguistics thesis or dissertation: a guide to presenting empirical research. Basingstoke: Palgrave Macmillan.

[31] Loi, C. K. (2010). Research article introductions in Chinese and English: a comparative genre-based study. Journal of English for Academic Purposes, 9(4), 267-279.

[32] Cotos, E., Huffman, S., \& Link, S. (2017). A move/step model for methods sections: Demonstrating rigor and credibility. English for Specific Purposes, 46, 90-106.

[33] Cruse, D. A. (1986). Lexical semantics. New York: Cambridge University Press.

i This Article is Sponsored by The Seed Foundation of Innovation and Creation for Graduate Students in Northwestern Polytechnical University 